\title{
Interaction Effects of Level and Instability of Motivation on Learning Strategies: Introjected and Identified Regulation
}

\author{
Takatoyo Umemoto ${ }^{1}$ \\ ${ }^{1}$ Faculty of Foreign Studies, Kyoto University of Foreign Studies, Kyoto, Japan \\ Correspondence: Takatoyo Umemoto, Faculty of Foreign Studies, Kyoto University of Foreign Studies, 6 \\ Kasame-cho, Saiin, Ukyo-ku, Kyoto 615-8558, Japan. Tel: 81-75-322-6133.
}

Received: September 13, 2021

Accepted: October 1, 2021 Online Published: October 8, 2021

doi:10.5539/jedp.v11n2p76

URL: http://doi.org/10.5539/jedp.v11n2p76

\begin{abstract}
This study examined the interaction effect of the level and instability of motivation on different learning strategies in university learning at the contextual level. Two motivation levels - introjected and identified regulation - and three types of learning strategies - metacognitive, writing-repetition, and deep-processing - were measured. Self-reported questionnaires were administered to students from two universities in Japan; data of 307 students were included in the analysis. A hierarchical multiple regression analysis on metacognitive and deep-processing strategies revealed an interaction effect of identified regulation and instability of motivation. The results of a simple slope analysis showed that identified regulation had no effect on metacognitive and deep-processing strategies during high instability of motivation. However, during low instability of motivation, higher identified regulation enabled greater use of metacognitive and deep-processing strategies. On the other hand, there was no an interaction effect of level and instability of motivation on writing-repetition strategies. These results revealed the significant role of the level and instability of motivation in the application of metacognitive and deep-processing strategies.
\end{abstract}

Keywords: level of motivation, introjected regulation, identified regulation, instability of motivation, learning strategies

\section{Introduction}

Several studies have revealed factors that influence learners' engagement. Motivation is an important factor for regulating learning and has been examined in several previous studies (e.g., Eccles \& Wigfield, 2002; Pintrich, 1999; Wentzel \& Miele, 2016). For example, Steinmayr et al. (2019) revealed that even after controlling for students' level of intelligence, motivation affects academic performance. So far, previous studies have only focused on the height (level) of motivation and lesser on the aspect of instability. Motivation is state dependent in a hierarchical model (Vallerand \& Lalande, 2011), but instability of motivation has not been fully conceptualized and examined. This leads to the question, "How does motivation level combined with instability, influence motivational consequences or learning engagement?" Clarifying these effects can provide suggestions for encouraging learning engagement from two aspects: motivation level and instability. Instability of motivation is a new perspective to facilitate learners' engagement. Therefore, this study examines the interaction effects of level and instability of motivation on learning strategies as motivational consequences in university learning, at the contextual level. In particular, this study focuses on two types of motivation level: introjected and identified regulation, which are conceptualized as in organismic integration theory, a sub-theory of self-determination theory. Figure 1 depicts the overview of this study. 


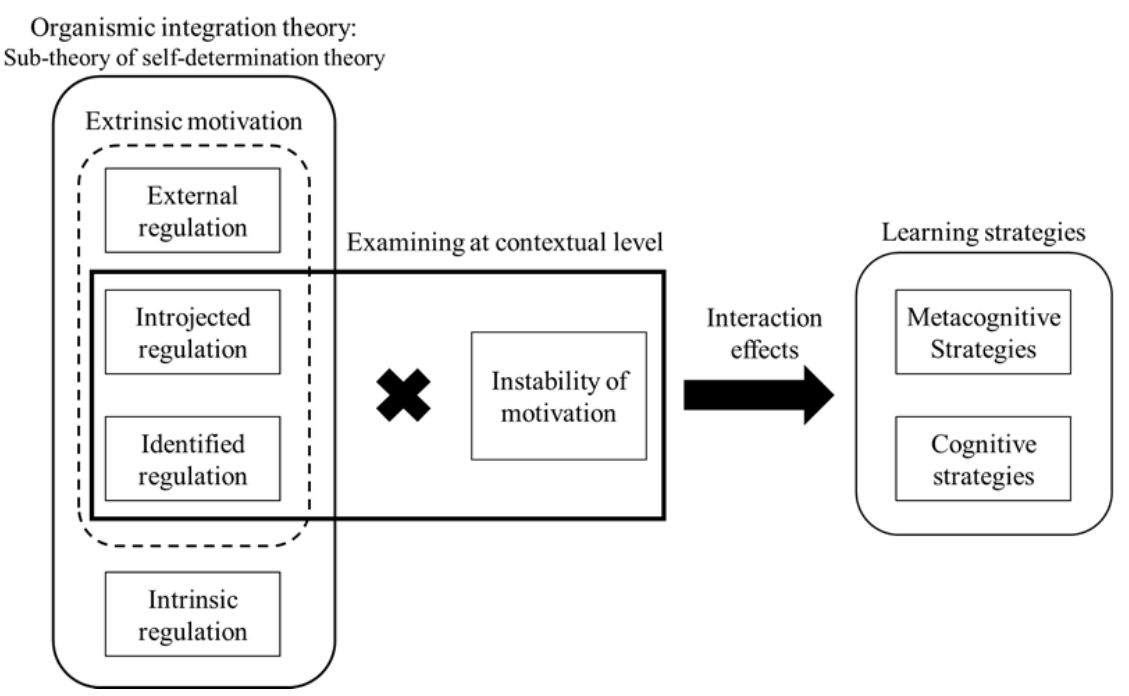

Figure 1. Overview of this study

\subsection{Introjected and Identified Regulation in Organismic Integration Theory}

Self-determination theory is one theory that addresses motivation level (Deci \& Ryan, 2002). Classically, motivation has been categorized as either intrinsic or extrinsic. However, organismic integration theory, a sub-theory of self-determination theory, locates both intrinsic motivation and extrinsic motivation within the single dimension of autonomy. The organismic integration theory posits that people developmentally and organismically tend to internalize and integrate ambient values and practices; moreover, the degree to which these values and practices are internalized affects a person's autonomy (Ryan et al., 2009). This theory divides extrinsic motivation into several types according to the degree of autonomy (Note 1). The first type is external regulation, which has the lowest level of autonomy. External regulation is a form of motivation based on external factors, such as acquisition of rewards, avoidance of punishment, and following social convention. This corresponds to what has been classically regarded as extrinsic motivation. The next type is introjected regulation, which involves a higher level of autonomy compared with external regulation. Further, it is based on avoidance of feelings such as guilt and shame as well as maintenance of self-worth based on comparisons with others, thus indicating partial internalization of the value of behaviors. The last type is identified regulation, which is a form of extrinsic motivation with greater autonomy compared with the two previously mentioned types. Identified regulation indicates recognition and internalization of the value of performing behaviors; moreover, it is based on the importance and usefulness of learning content. Intrinsic regulation refers to intrinsic motivation based on the pleasure and satisfaction derived from participation and performing an activity as an end to itself (Vallerand et al., 1992). The three types of extrinsic motivation and intrinsic motivation are positioned on a continuum with dimensions arranged according to their relative degree of autonomy, starting with external regulation, and followed by introjected regulation, identified regulation, and intrinsic regulation, in that order. Previous studies have examined the relationship between the aforementioned types of motivations and learning strategies, engagement, educational adjustment, well-being, and academic achievement (e.g., Guay et al., 2008; Komarraju et al., 2009; Nishimura et al., 2011; Otis et al., 2005; Walker et al., 2006; Walls \& Little, 2005). Further, they have revealed that higher external regulation and introjected regulation lead to maladaptive learning, whereas higher identified regulation and intrinsic regulation often lead to adaptive learning.

In classical studies of motivation predating self-determination theory, extrinsic motivation was defined mainly in terms of external regulation. However, introjected and identified regulation are relatively new types of motivation that have not yet been studied as extensively as external regulation. Thus, it is important to focus on them to build knowledge about their role in learning as well as to understand the motivation in learning from the perspective of introjected and identified regulation, thus elucidating the process of motivation in learning.

\subsection{Instability of Motivation}

Previous studies on motivation, including those based on organismic integration theory, have focused primarily on the level of motivation. However, motivation is not a psychological process by which a particular level is consistently maintained. Vallerand and Lalande (2011) assumed that motivation in a particular context (e.g., school learning) and motivation for a particular activity is more state dependent and less stable than motivation in general 
(e.g., personality). For instance, Manalo et al. (2006) revealed that Japanese university students hold negative views and are therefore more likely to enroll in university for extraneous reasons (e.g., because I do not want to work yet) compared with university students in New Zealand. Such negative views and extrinsic reasons for enrolling at university may affect their motivation and the instability of motivation in daily learning. While on some days, there may be no desire to engage in learning, on other days, motivation may increase temporarily due to interest in the learning contents or the desire to attain good scores in the next examination. Okada et al. (2015) addressed these changes by proposing the concept of "instability of motivation," which highlights the fluctuation of motivation over time. Previous studies, such as those measuring the level of motivation, captured only the stable aspects of motivation and rarely measured individual differences in instability of motivation using a scale. For Japanese university students, Okada et al. (2015) measured the instability of motivation for university learning using a self-evaluation scale and considered its correlation with procrastination. The results indicated that the greater the instability of motivation, the greater was the tendency to procrastinate, thus suggesting that when motivation is unstable, learners first attempt to stabilize motivation, resulting in procrastination of the learning task.

Previous studies have also examined the factors influencing instability of motivation. Umemoto and Inagaki (2019) examined the relationship between motivational regulation strategies and instability of motivation during classroom lessons. Motivational regulation strategies are a type of learning strategy that aid in increasing effort and persistence and regulating one's motivation during learning (e.g., Miele \& Scholer, 2017). Prior studies have revealed that such strategies affect effort, cognitive strategies, emotional engagement, and academic achievement (e.g., Schwinger \& Stiensmeier-Pelster, 2012; Umemoto, 2013; Umemoto et al., 2016; Wolters, 1999). Motivational regulation strategies are related to low instability of motivation (Umemoto \& Inagaki, 2019), indicating that using motivational regulation strategies could possibly prevent a decrease in motivation during learning. Moreover, Okada et al. (2015) demonstrate that the higher the tendency to monitor one's own motivation, the more likely learners are to perceive their instability of motivation. This is consistent with the finding that people who tend to pay attention to their emotion have a high self-evaluation for their affective instability (Thompson et al., 2009). Thus, instability of motivation presents a new perspective on motivation, which few studies addressed. Therefore, studies on instability of motivation are needed to clarify the process of motivation in learning.

Studies on instability of motivation have considered the interaction effect of the "level" and "instability" of self-esteem. For instance, Kernis et al. (1991) and Ichimura (2012) examined the interaction effect of the levels and instability of self-esteem on feelings of depression. Thus, it can be hypothesized that the level and instability have an interaction effect with motivation as well. This interaction effect enables us to understand the process of motivation in learning in greater detail.

\subsection{The Contextual Level of the Three Levels of Motivation}

Recently, several studies have analyzed motivation across three levels in a hierarchical model (Vallerand \& Lalande, 2011): global, contextual, and situational levels. The global level is the most general and is equivalent to one's personality. This level of motivation implies a temperamental and characteristic approach toward activities in general. The contextual level includes motivation in the context of daily life (e.g., education, leisure, and interpersonal relationships). For instance, motivation toward school learning may be placed at the contextual level. Finally, the situational level represents motivation to engage in a particular activity or situation. For example, learning motivation toward certain classes, activities, and tasks may be placed at the situational level.

Previous studies have examined the relationship between the three levels of motivation. Vallerand and Lalande (2011) posited that there is a bottom-up effect from lower to higher levels (e.g., situational to contextual level), as well as a top-down effect from higher to lower levels (e.g., global to contextual level). In a six-point longitudinal survey, Núñez and León (2018) investigated the top-down and bottom-up effects between global motivation (e.g., personality), contextual motivation at a university, and situational motivation in specific tasks/activities at university. These studies show the importance of examining motivational processes by distinguishing between three levels of motivation. The Vallerand and Lalande (2011) hierarchical model hypothesized a link between motivation at one level and motivational consequences at the same level. For example, Guay et al. (2000) examined the relationship between situational motivation and concentration during a task. The correlation analysis indicated that intrinsic and identified regulation were positively associated with concentration; moreover, external regulation was negatively associated with concentration at the situational level. Therefore, it is important to consider the relationship between motivation and motivational consequences within the same level.

In the hierarchical model, motivation at the contextual and situational level is relatively state dependent or momentary, compared to stable, global level motivation (Vallerand \& Lalande, 2011). That is, instability of 
motivation should be examined at both the contextual and situational level. Previous studies (e.g., Umemoto \& Inagaki, 2019, 2021) have examined instability of motivation and motivational consequences and learning engagement (e.g., learning strategies) at the situational level, but not at the contextual level. Therefore, it is important to clarify the effects of instability of motivation on motivational consequences at the contextual level (e.g., school learning).

\subsection{Metacognitive and Cognitive Learning Strategies as Motivational Consequences}

Learning strategies are conceptualizations of the ways through which individuals approach learning. Previous studies have shown that learners use a variety of learning strategies (e.g., Pintrich et al., 1993; Weinstein \& Mayer, 1986; Zimmerman \& Partinez-Pons, 1986). The present study focuses on metacognitive and cognitive strategies (surface- and deep-processing strategies). In metacognitive strategies, individuals monitor and control their own cognitive activity. This includes planning (setting goals), monitoring to grasp their own understanding and regulating their own behavior/cognition (Pintrich et al., 1993). Cognitive strategies, including surface- and deep-processing strategies, are used to remember and understand learning content (Marton \& Säljö, 1976; Murayama, 2003). Surface-processing strategies are learning strategies in which memorization is applied without understanding through simple repetition of learning content. Deep-processing strategies are learning methods that promote the understanding of learning contents based on the associations between new information and existing knowledge. Therefore, learning strategies are important factors affecting academic achievement (e.g., Pintrich \& De Groot, 1990; Pokay \& Blumenfeld, 1990). In particular, previous studies have shown that metacognitive strategies and deep-processing strategies encourage academic achievement (e.g., Murayama et al., 2013; Nishimura et al., 2011; Vansteenkiste et al., 2004).

Moreover, prior studies have also revealed the factors influencing the use of learning strategies. For example, Komarraju et al. (2011) examined the relationship between the Big Five personality traits and learning strategies in university students. The results indicated that openness and conscientiousness were positively related with the use of learning strategies. Moreover, many previous studies demonstrated that motivation is an important factor in facilitating the use of learning strategies. (e.g., Pintrich, 1999). Vansteenkiste et al. (2009) revealed that the autonomous motivation (e.g., identified regulation and intrinsic regulation) was positively related to metacognitive strategies, whereas controlled motivation (such as external regulation and introjected regulation) was not related to metacognitive strategies. In addition, Vansteenkiste et al. (2004) revealed the positive relationship between autonomous motivation and deep-processing strategies, and the negative relationship between autonomous motivation and surface-processing strategies. Moreover, Nishimura et al. (2011) revealed that identified regulation was positively associated with metacognitive strategies in junior high school students. However, no relationship between external regulation, introjected, regulation, intrinsic regulation, and metacognitive strategies was found in the study. Therefore, there is a need to clarify the process of using learning strategies through their correlation with motivation to facilitate effective learning.

Although most studies focus only on the level of motivation, Umemoto and Inagaki (2021) studied the interaction effect of level and instability of motivation for learning in a specific university class on deep-processing strategies and academic achievement during the class, which is positioned at the situational level. Through a hierarchical multiple regression analysis, they revealed that the level and instability of motivation have a significant interaction effect on deep-processing strategies. However, no interaction effect on academic achievement was found, indicating that the interaction between the level and instability of motivation seems to particularly affect engagement with learning. While Umemoto and Inagaki's study examined the situational level, thus far, no other study has examined the interaction effect of the level and instability of motivation on learning engagement at other levels. Therefore, to gain a deeper understanding of the learning motivation process, it is necessary to study the interaction effect with a focus on the contextual level. Moreover, Umemoto and Inagaki (2021) did not consider the type of motivation level (e.g., identified regulation). Thus, to clarify the process of using learning strategies, it is necessary to examine the relationship between the various types of motivation levels and instability of motivation and the use of learning strategies.

\subsection{Purpose of the Present Study}

This study aimed to examine the interaction effect of introjected regulation, identified regulation, and instability of motivation on learning strategies (metacognitive, surface-processing, and deep-processing) in university learning, which is positioned at the contextual level in the hierarchical model. This study posits the following hypotheses: (1) the level of motivation has no effect on learning strategies when instability of motivation is high; (2) the level of motivation has a significant effect on learning strategies when the instability of motivation is low; and (3) in particular, learning strategies are used most when the motivation is stable and high. These hypotheses are based on the studies of Kernis et al. (1991), Ichimura (2012), and Okada et al. (2015). In Kernis et al. (1991) and Ichimura 
(2012), although self-esteem levels did not have an effect on depressive symptoms when the instability of self-esteem was high, such levels had a significant negative effect on depressive symptoms when the instability was low. These studies indicated that stable and high self-esteem was the most adaptive. Since Okada et al. (2015) suggested that instability of motivation has a negative effect on learning. The present study adopts the view that the use of learning strategies would not increase when the instability of motivation is high, even if the motivational level is high. In addition, results of previous studies (e.g., Nishimura et al., 2011; Vansteenkiste et al., 2004) have demonstrated that identified regulation shows a stronger positive association, especially with metacognitive strategies and deep-processing strategies compared with introjected regulation.

\section{Method}

\subsection{Participant and Survey Procedure}

A total of 307 students from two Japanese universities (150 students from University A and 157 students from University B) were included in the analysis. University A was a private university located in the Kansai region, while University B was a national university located in the Kyushu region in Japan. The sample included 52 first-year students, 180 second-year students, 59 third-year students, and 15 fourth-year students. Among them, there were 158 males, 143 females, and 5 individuals who did not indicate their gender. Their average age was $19.53(S D=1.36)$. Self-administered questionnaires were distributed in various university classes and collected on the spot after students completed them. The survey was conducted in May 2019.

The first sheet of the questionnaire explicitly stated, "There are no correct or incorrect answers. You may choose to not answer certain questions." Participants were given information regarding the research study; they provided written informed consent for their participation. Participants were given the option not to participate in the study. Moreover, the participants were informed that there were no negative consequences for withdrawing from the study at any point. Participants did not receive any reward for participating. This study has not undergone an ethical review, as there was no ethical review board at the university with which the authors are affiliated. However, prior to conducting the study, a third-party psychologist reviewed the contents of the study and verified the study as being ethically acceptable. The survey was anonymous and conducted during the class time. Further, students who chose not to participate in the survey were instructed to wait until the survey was completed.

\subsection{Survey Content}

For all the following scales, responses were rated on a five-point Likert-scale from not applicable (1) to very applicable (5). All scale items translated from Japanese to English are shown in the appendix.

\subsubsection{Level of Motivation}

Items from a learning motivation scale for Japanese university students (Okada \& Nakaya, 2006) were used to measure introjected regulation (15 items) and identified regulation (4 items). The scale was developed based on self-determination theory (Deci \& Ryan, 2002). The instructions were "This question concerns learning and studying various things on a daily basis through university classes, club activities, qualification examination preparation, and so on. Why do you perform this type of learning or studying activity?" The internal consistency of the scale was confirmed; the content validity was confirmed by university psychology professors who assessed the content of the items (Okada \& Nakaya, 2006). Okada and Nakaya (2006) analyzed data from 335 students attending university in Japan. Because the participants in Okada and Nakaya's (2006) study are similar to those of the present study, Okada and Nakaya's (2006) study can be used as evidence of the reliability and validity of the scales in this study.

\subsubsection{Instability of Motivation}

A scale by Okada et al. (2015) was used to measure the instability of motivation in the context of university learning (5 items). The scale was developed based on the stability of self scale (e.g., Oshio, 2001; Rosenberg, 1965). A high value of this variable indicates that motivation toward university learning changes easily. The internal consistency of the scale was confirmed; further, the construct validity of the scale was confirmed through its association with the instability of motivation, which was calculated from multiple measurements of motivation (Okada et al., 2015). Okada et al. (2015) analyzed data from 299 students at a four-year university in Japan. Because the participants of Okada et al.'s (2015) study are similar to those of this study, Okada et al.'s (2015) study can be used as evidence of the reliability and validity of the scales in the present study.

\subsubsection{Metacognitive Strategies}

A scale by Umemoto (2013) was used to measure the use of metacognitive strategies in the context of university learning (6 items). This scale includes items measuring both planning and monitoring, which are important elements of metacognitive strategies (e.g., Pintrich et al., 1993). The internal consistency of the scale was 
confirmed by calculating the $\alpha$ coefficient (Umemoto, 2013). Umemoto (2013) analyzed data from 197 students attending a four-year university in Japan. Because the participants of Umemoto's (2013) study are similar to those of this study, Umemoto's (2013) study can be used as evidence of the reliability of the scales in the current study. Moerover, Umemoto and Yada (2012) confirmed the one-factor structure of the scale by factor analysis.

\subsubsection{Cognitive Strategies}

A scale by Umemoto (2013) was used to measure the use of cognitive strategies in the context of university learning. This scale includes two subscales: the surface-processing strategy of writing-repetition in which learning content is learned by writing it repeatedly ( 3 items) and the deep-processing strategy in which learning content is learned by associating new information with existing knowledge (6 items). The internal consistency of the scale was confirmed (Umemoto, 2013); further, Umemoto and Yada (2012) confirmed the two-factor structure of the scale by factor analysis.

\section{Results}

\subsection{Structure of the Scale and the Differences Between the Universities}

First, to confirm the internal consistencies of each subscale, $\alpha$ coefficients were calculated (Table 1). As sufficiently high values were obtained, the scales used in this study were considered to have sufficient reliability. However, for the identified regulation, the $\alpha$ coefficient was slightly low. The subscales were structured using the mean of each item. The mean value, standard deviation, and $\alpha$ coefficient of each subscale are shown in Table 1. The results of the correlation analysis are shown in Table 2. No significant correlation was found between the two motivations and the instability of motivation. However, positive correlations were found between the two motivations and the three learning strategies.

Table 1. Means, SDs, and alpha coefficients of each subscale

\begin{tabular}{lcccc}
\hline & Mean & $S D$ & $\alpha$ & $N$ \\
\hline Introjected regulation & 3.20 & 0.60 & .84 & 300 \\
Identified regulation & 3.89 & 0.65 & .68 & 306 \\
Instability of motivation & 3.80 & 0.80 & .85 & 298 \\
Metacognitive strategies & 3.50 & 0.67 & .74 & 306 \\
Writing-repetition strategies & 3.59 & 0.93 & .80 & 306 \\
Deep-processing strategies & 3.78 & 0.59 & .76 & 305 \\
\hline
\end{tabular}

Table 2. Results of a correlation analysis

\begin{tabular}{|c|c|c|c|c|c|c|c|c|c|c|c|}
\hline & & \multicolumn{2}{|c|}{1} & \multicolumn{2}{|c|}{2} & \multicolumn{2}{|c|}{3} & \multicolumn{2}{|c|}{4} & \multicolumn{2}{|c|}{5} \\
\hline 2 & Identified regulation & .38 & $* * *$ & & & & & & & & \\
\hline 3 & Instability of motivation & .06 & & -.08 & & & & & & & \\
\hline 4 & Metacognitive strategies & .21 & $* * *$ & .31 & $* * *$ & -.22 & $* * *$ & & & & \\
\hline 5 & Writing-repetition strategies & .14 & $*$ & .14 & $*$ & .09 & & .17 & $* *$ & & \\
\hline 6 & Deep-processing strategies & .13 & $*$ & .24 & $* * *$ & -.05 & & .69 & $* * *$ & .24 & $* * *$ \\
\hline
\end{tabular}

Note. ${ }^{*} p<.05,{ }^{* *} p<.01,{ }^{* * *} p<.001$.

Second, unpaired $t$-test using the university as the independent variable was conducted (Table 3 ). The results revealed that, for identified regulation, the mean value was higher for University A than for University B. For metacognitive strategies and deep-processing strategies, the mean value was found to be higher for University B than for University A. Based on these results, as differences in learning between universities were expected, further analyses used the university as a control variable. 
Table 3. $t$-test results

\begin{tabular}{|c|c|c|c|c|c|c|c|c|c|}
\hline & \multicolumn{3}{|c|}{ University A } & \multicolumn{3}{|c|}{ University B } & \multirow{2}{*}{\multicolumn{2}{|c|}{$t$-value }} & \multirow{2}{*}{$\begin{array}{c}\text { Headges' } \\
g\end{array}$} \\
\hline & Mean & $S D$ & $n$ & Mean & $S D$ & $n$ & & & \\
\hline Introjected regulation & 3.21 & 0.59 & 145 & 3.19 & 0.61 & 155 & 0.23 & & 0.03 \\
\hline Identified regulation & 4.05 & 0.61 & 149 & 3.75 & 0.65 & 157 & 4.16 & $* * *$ & 0.48 \\
\hline Instability of motivation & 3.88 & 0.77 & 142 & 3.73 & 0.82 & 156 & 1.64 & & 0.19 \\
\hline Metacognitive strategies & 3.39 & 0.71 & 149 & 3.61 & 0.60 & 157 & -2.84 & $* *$ & 0.34 \\
\hline Writing-repetition strategies & 3.63 & 0.93 & 149 & 3.56 & 0.94 & 157 & 0.70 & & 0.07 \\
\hline Deep-processing strategies & 3.63 & 0.64 & 149 & 3.92 & 0.50 & 156 & -4.40 & $* * *$ & 0.51 \\
\hline
\end{tabular}

Note. ${ }^{* *} p<.01, * * * p<.001$.

\subsection{Relationship between Motivation, Instability of Motivation, and Learning Strategies}

To investigate the associations among the two motivations, the instability of motivation, and the three learning strategies, a hierarchical multiple regression analysis was conducted. In Step 1, the university (University A was dummy coded as " 0.5 " and University B was dummy coded as "- 0.5 ") was introduced as the control variable. In Step 2, introjected regulation, identified regulation, and instability of motivation were introduced. Finally, in Step 3 , interaction items between the two motivations and the instability of motivation were introduced.

With regard to metacognitive strategies, the degree of change in the coefficient of determination from Step 2 to Step 3 was significant $\left(\Delta R^{2}=.05, p<.001\right)$. In Step 3, the coefficient of determination was also significant $\left(R^{2}=.25\right.$, $p<.001)$. Step 3 revealed the main effects of introjected and identified regulation, and instability of motivation as well as the interaction effect of identified regulation and instability of motivation on metacognitive strategies were significant (Table 4). The results of a simple slope analysis showed that when instability of motivation was high, the degree of strategy usage did not change based on the level of identified regulation $(b=0.10, S E=0.08, p=.19)$. However, when the instability of motivation was low, a higher identified regulation resulted in a greater degree of strategy usage $(b=0.51, S E=0.08, p<.001$; Figure 2$)$.

Table 4. Hierarchical multiple regression analysis results, metacognitive strategies as the dependent variable $(N=291)$

\begin{tabular}{|c|c|c|c|c|c|c|c|c|}
\hline & \multicolumn{2}{|c|}{$b$} & $S E$ & \multicolumn{5}{|c|}{$95 \% \mathrm{CI}$} \\
\hline$\underline{\text { Step } 1}$ & \multicolumn{7}{|c|}{ Criterion: Metacognitive starategies } & \\
\hline University & -0.24 & $* *$ & 0.08 & {[} & -0.39 & , & -0.09 & ] \\
\hline \multicolumn{9}{|l|}{$R^{2}=.03 * *$} \\
\hline \multicolumn{9}{|l|}{ Step 2} \\
\hline University & -0.30 & $* * *$ & 0.07 & {[} & -0.44 & , & -0.16 & ] \\
\hline Introjected regulation & 0.13 & $*$ & 0.06 & {[} & 0.00 & , & 0.25 & ] \\
\hline Identified regulation & 0.30 & $* * *$ & 0.06 & {[} & 0.18 & , & 0.41 & ] \\
\hline Instability of motivation & -0.16 & $* * *$ & 0.04 & {[} & -0.25 & , & -0.08 & ] \\
\hline \multicolumn{9}{|l|}{$R^{2}=.20 * * *$} \\
\hline \multicolumn{9}{|l|}{$\Delta R^{2}=.17 * * *$} \\
\hline \multicolumn{9}{|l|}{ Step 3} \\
\hline University & -0.30 & $* * *$ & 0.07 & {[} & -0.43 & , & -0.16 & ] \\
\hline Introjected regulation & 0.12 & $*$ & 0.06 & {[} & 0.00 & , & 0.24 & ] \\
\hline Identified regulation & 0.30 & $* * *$ & 0.06 & {[} & 0.19 & , & 0.42 & ] \\
\hline Instability of motivation & -0.17 & $* * *$ & 0.04 & {[} & -0.26 & , & -0.09 & ] \\
\hline Introjected regulation $\times$ Instability of motivation & 0.05 & & 0.07 & {[} & -0.09 & , & 0.18 & ] \\
\hline Identified regulation $\times$ Instability of motivation & -0.26 & $* * *$ & 0.07 & {[} & -0.39 & , & -0.13 & ] \\
\hline \multicolumn{9}{|l|}{$R^{2}=.25 * * *$} \\
\hline$\Delta R^{2}=.05 * * *$ & & & & & & & & \\
\hline
\end{tabular}




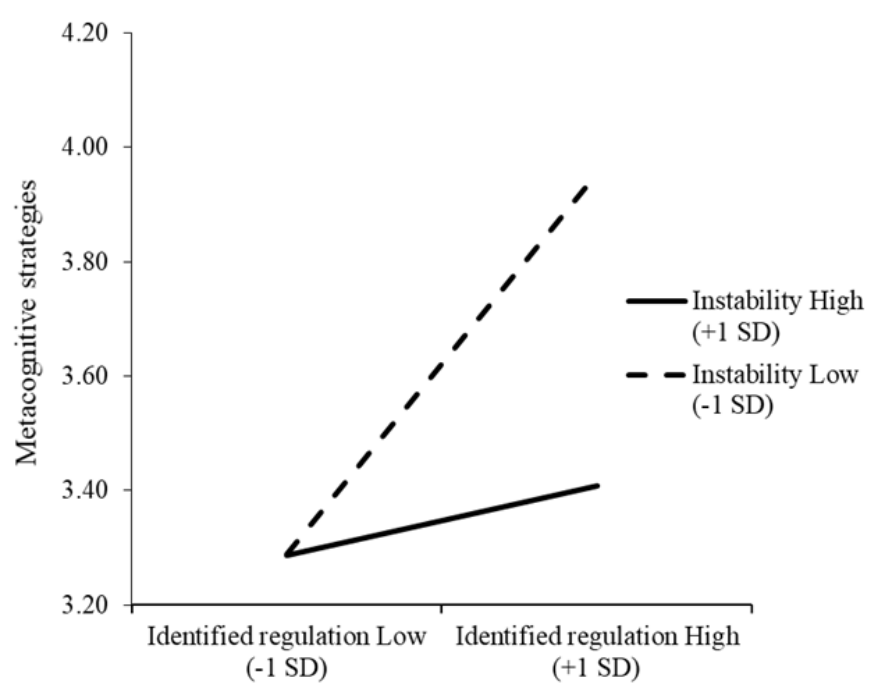

Figure 2. Simple slope analysis of metacognitive strategies

With regard to writing-repetition strategies, the degree of change in the coefficient of determination from Step 2 to Step 3 was not significant $\left(\Delta R^{2}=.00, p=.79\right)$. The coefficient of determination was also not significant in Step 3 $\left(R^{2}=.04, p=.07\right)$. In Step 2, neither main effect was significant (Table 5).

Finally, with regard to deep-processing strategies, the degree of change in the coefficient of determination from Step 2 to Step 3 was significant $\left(\Delta R^{2}=.05, p<.001\right)$. The coefficient of determination was also significant in Step 3 $\left(R^{2}=.20, p<.001\right)$. In Step 3, for deep-processing strategies, identified regulation was found to have a significant main effect, while identified regulation and instability of motivation were found to have a significant interaction effect (Table 6). The simple slope analysis revealed that when the instability of motivation was high, the degree of strategy usage did not change based on the level of identified regulation $(b=0.07, S E=0.07, p=.35)$. However, when the instability of motivation was low, a higher identified regulation resulted in a greater degree of strategy usage $(b=0.48, S E=0.07, p<.001$; Figure 3).

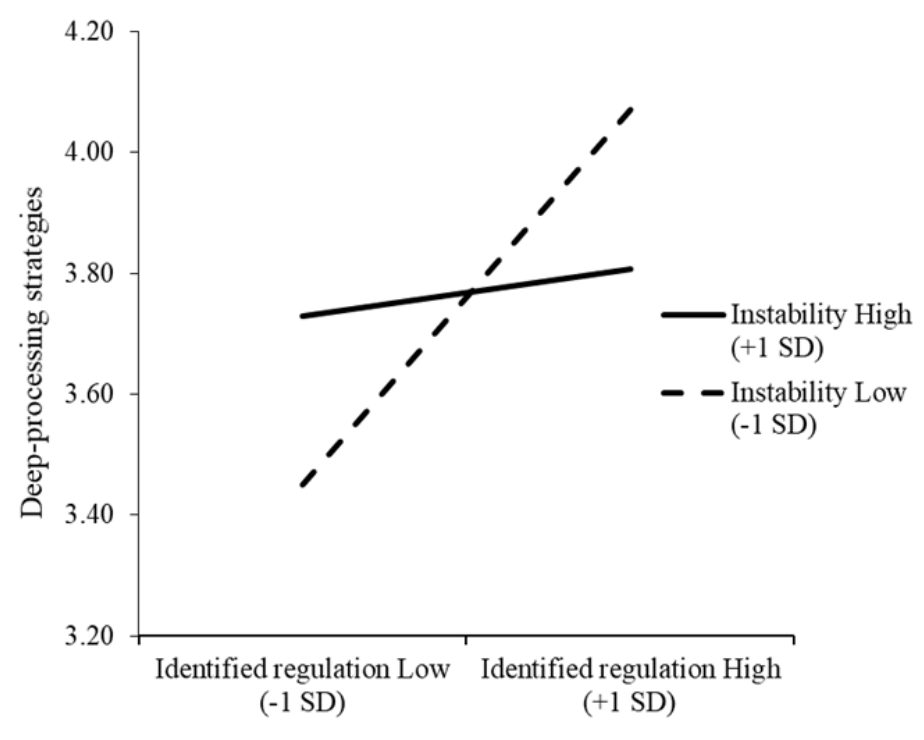

Figure 3. Simple slope analysis of deep-processing strategies 
Table 5. Hierarchical multiple regression analysis results, writing-repetition strategies as the dependent variable $(N=291)$

\begin{tabular}{|c|c|c|c|c|c|c|c|}
\hline & $b$ & $S E$ & \multicolumn{5}{|c|}{$95 \% \mathrm{CI}$} \\
\hline$\underline{\text { Step } 1}$ & \multicolumn{6}{|c|}{ Criterion: Writing-repetition strategies } & \\
\hline University & 0.07 & 0.11 & {[} & -0.15 & , & 0.28 & ] \\
\hline \multicolumn{8}{|l|}{$R^{2}=.00$} \\
\hline \multicolumn{8}{|l|}{$\underline{\text { Step } 2}$} \\
\hline University & 0.01 & 0.11 & {[} & -0.21 & , & 0.23 & ] \\
\hline Introjected regulation & 0.15 & 0.10 & {[} & -0.04 & , & 0.34 & ] \\
\hline Identified regulation & 0.14 & 0.09 & {[} & -0.04 & , & 0.32 & ] \\
\hline Instability of motivation & 0.11 & 0.07 & {[} & -0.02 & , & 0.25 & ] \\
\hline \multicolumn{8}{|l|}{$R^{2}=.04 *$} \\
\hline \multicolumn{8}{|l|}{$\Delta R^{2}=.04 *$} \\
\hline \multicolumn{8}{|l|}{$\underline{\text { Step } 3}$} \\
\hline University & 0.01 & 0.11 & {[} & -0.43 & , & -0.16 & ] \\
\hline Introjected regulation & 0.15 & 0.10 & {[} & 0.00 & , & 0.24 & ] \\
\hline Identified regulation & 0.14 & 0.09 & {[} & 0.19 & , & 0.42 & ] \\
\hline Instability of motivation & 0.11 & 0.07 & {[} & -0.26 & , & -0.09 & ] \\
\hline Introjected regulation $\times$ Instability of motivation & -0.02 & 0.11 & {[} & -0.09 & , & 0.18 & ] \\
\hline Identified regulation $\times$ Instability of motivation & -0.06 & 0.10 & {[} & -0.39 & , & -0.13 & ] \\
\hline \multicolumn{8}{|l|}{$R^{2}=.04$} \\
\hline$\Delta R^{2}=.00$ & & & & & & & \\
\hline
\end{tabular}

Table 6. Hierarchical multiple regression analysis results, deep-processing strategies as the dependent variable $(N=290)$

\begin{tabular}{|c|c|c|c|c|c|c|c|c|}
\hline \multirow{2}{*}{$\underline{\text { Step } 1}$} & \multicolumn{2}{|c|}{$b$} & \multicolumn{2}{|l|}{$S E$} & \multicolumn{4}{|c|}{$95 \% \mathrm{CI}$} \\
\hline & \multicolumn{8}{|c|}{ Criterion: Deep-processing strategies } \\
\hline & -0.30 & $* * *$ & 0.07 & {[} & -0.43 & , & -0.17 & ] \\
\hline \multicolumn{9}{|l|}{$R^{2}=.07 * * *$} \\
\hline \multicolumn{9}{|l|}{ Step 2} \\
\hline University & -0.37 & $* * *$ & 0.07 & {[} & -0.50 & , & -0.24 & ] \\
\hline Introjected regulation & 0.02 & & 0.06 & {[} & -0.09 & , & 0.13 & ] \\
\hline Identified regulation & 0.26 & $* * *$ & 0.05 & {[} & 0.15 & , & 0.37 & ] \\
\hline Instability of motivation & 0.00 & & 0.04 & {[} & -0.08 & , & 0.08 & ] \\
\hline \multicolumn{9}{|l|}{$R^{2}=.15 * * *$} \\
\hline \multicolumn{9}{|l|}{$\Delta R^{2}=.08 * * *$} \\
\hline \multicolumn{9}{|l|}{ Step 3} \\
\hline University & -0.36 & $* * *$ & 0.06 & {[} & -0.49 & , & -0.24 & ] \\
\hline Introjected regulation & 0.01 & & 0.06 & {[} & -0.10 & , & 0.12 & ] \\
\hline Identified regulation & 0.27 & $* * *$ & 0.05 & {[} & 0.16 & , & 0.37 & ] \\
\hline Instability of motivation & 0.00 & & 0.04 & {[} & -0.07 & , & 0.08 & ] \\
\hline Introjected regulation $\times$ Instability of motivation & 0.10 & & 0.06 & {[} & -0.02 & , & 0.23 & ] \\
\hline Identified regulation $\times$ Instability of motivation & -0.26 & $* * *$ & 0.06 & {[} & -0.38 & , & -0.14 & ] \\
\hline \multicolumn{9}{|l|}{$R^{2}=.20 * * *$} \\
\hline$\Delta R^{2}=.05 * * *$ & & & & & & & & \\
\hline
\end{tabular}




\section{Discussion}

The present study focused on university students and examined the interaction effect of introjected regulation, identified regulation, and instability of motivation on learning strategies, as measured through university learning, which was positioned at the contextual level.

\subsection{Relationship Between Motivation, Instability of Motivation and Learning Strategies}

The results of the hierarchical multiple regression analysis revealed that identified regulation and instability of motivation had an interaction effect on metacognitive strategies and deep-processing strategies. Specifically, when the instability of motivation was low, a higher level of identified regulation resulted in a greater use of learning strategies. Additionally, when identified regulation was high and the instability of motivation was low, the use of learning strategies was the highest. These results align with those of Kernis et al. (1991) and Ichimura (2012), who investigated the interaction of levels and instability of self-esteem, and demonstrated that high and stable self-esteem was the most adaptive. Thus, students engage more proactively in learning and are better able to continually make use of effective learning strategies when identified regulation stabilizes at a high level than when it stabilizes at a low level. Previous studies found that greater identified regulation compels learners to use learning strategies (e.g., Nishimura et al., 2011). The present study not only confirmed this, but also found that the degree of fluctuation of motivation is significant in the use of learning strategies. Therefore, it is important to investigate the instability of motivation along with the level of motivation. Given that very few studies have examined the role of instability of motivation in learning, this study will enable future research on motivation.

However, when the instability of motivation was high, regardless of whether the level of identified regulation was high or low, the degree to which students employed learning strategies did not change. This result suggests that even with a high level of identified regulation and instability of motivation, it is difficult to continuously use learning strategies effectively. This result is consistent with Okada et al.'s (2015) finding that the instability of motivation has a negative effect on learning. To continually use learning strategies for ordinary learning in an effective manner, it is necessary to consider not only the level, but also the low instability of motivation. Thus, these results indicate that it may be possible to encourage learning by considering the degree of fluctuation of motivation and provide educational avenues with a novel perspective. For example, the instability of motivation can be suppressed by equipping students with strategies for regulating motivation, and instructing them to use them during learning (e.g., Umemoto and Inagaki, 2019). Many studies have examined teaching methods for increasing the level of motivation (e.g., autonomy support, involvement, and structure to increase the level of autonomous motivation; Deci \& Ryan, 2002; Guay et al., 2008). However, methods to suppress instability of motivation have not yet been fully investigated. Therefore, it is necessary to clarify the factors influencing the instability of motivation in school learning.

Moreover, this study found an interaction effect between the level and instability of motivation for identified regulation but not for introjected regulation. This result is consistent with the findings of Vansteenkiste et al. (2009), which revealed that controlled motivation (e.g., introjected regulation) was not associated with learning strategies; however, autonomous motivation (e.g., identified regulation) positively affected the use of learning strategies. Identified regulation is a type of motivation based on the importance and usefulness of learning content; moreover, it has an interesting correlation with future careers. In particular, as the participants of this study were about to begin their careers and become contributing members of society, the low instability of identified regulation is likely to be linked to the active use of learning strategies. In other words, if the content of current learning is evaluated consistently as significant and useful to the future careers of university students, the use of metacognitive and deep-processing strategies may provide a deeper level of encouragement. In the future, it is also necessary to examine the interaction effect of identified regulation and instability of motivation among high school, middle school, and elementary school students. On the other hand, introjected regulation was found to have no interaction effect with the instability of motivation for learning strategies. However, it did have a positive correlation with metacognitive strategies, thus indicating that introjected regulation, a form of motivation founded on maintenance of self-worth based on comparisons with others as well as avoidance of feelings of guilt and shame, may also encourage learning. Although Vansteenkiste et al. (2009) showed that controlled motivation was not related to metacognitive strategies, Assor et al. (2009) indicated that introjection regulation facilitates learning. For example, Nishimura et al. (2011) found a positive correlation between introjection regulation and academic performance in junior high school students. In the future, a detailed investigation on the encouragement of learning using introjected regulation must be conducted.

Additionally, for writing-repetition strategies, motivation level and instability of motivation were found not to have an interaction effect. It is possible that the quality of learning strategies is a factor in this finding. As 
metacognitive strategies are learning strategies that control learning and monitor comprehension, while deep-processing strategies are learning strategies that form links between learning content, they demand significant cognitive resources. Therefore, sufficient cognitive resources are needed to use these strategies, effectively. This is consistent with the cognitive load theory which states that cognitive load affects processing tasks (e.g., Sweller, 1994). Seufert (2018) revealed the association between the three types of cognitive load (intrinsic, extraneous, and germane) and the use of cognitive and metacognitive strategies. Therefore, this study indicated that reducing cognitive load facilitates the self-regulation process (e.g., use of metacognitive strategies). In the present study, when motivation is stable rather than when the instability of motivation is high, the learner can concentrate on continuously processing the learning task, thus reducing the cognitive load. In this case, sufficient cognitive resources can be made available to use deep-processing and metacognitive strategies, effectively. Therefore, the higher the level of motivation, the greater is the use of these strategies. On the other hand, as writing-repetition strategies are surface-processing strategies that merely involve repeatedly writing learning content until it is memorized, they require relatively fewer cognitive resources. Thus, the instability of motivation may mostly be unimportant for writing-repetition strategies. In the future, it will be worthwhile to investigate the direct correlation between the instability of motivation, cognitive resources, and cognitive loads.

\subsection{Limitations of the Present Study and Future Challenges}

The limitations of the present study, as well as future challenges, are as follows. First, the results of the present study should be generalized with caution. As similar studies have been conducted on many occasions, it is necessary to investigate the reproducibility and soundness of the study results. In addition, further confirmation regarding the reliability and validity of the scales used in this study are needed to ensure that the results are generalizable. For example, the $\alpha$ coefficient of identified regulation was slightly low. Therefore, the item contents for identified regulation need improvement through future research. In this study, no class year difference was examined to capture the general tendency of university students. Future studies should examine the differences in the instability of motivation by class year; moreover, they should investigate the relationship between the instability of motivation and learning behaviors by class year. Second, in the future, it will be necessary to devise a means of measuring the instability of motivation as the present study only used scales. A previous study on the situational level of motivation (Umemoto \& Inagaki, 2021), measured in-class situational motivation several times by referring to the measurement methods of studies on instability of self-esteem and considering variations in individuals' internal standards as indicators of the instability of motivation. For instance, at the contextual level, it is important to measure motivation multiple times across several weeks or months, as well as calculate and investigate the instability of motivation. Third, it is worth noting that the present study examined the instability of general motivation for learning rather than that of introjected and identified regulation. Future studies should focus on determining the instability of introjected and identified regulation directly, while considering their interaction effects with levels. It is necessary to develop these scales by referring to self-determination theory as well as previous studies on the instability of motivation while also verifying their reliability and validity.

Fourth, the present study focused on the correlation between the level and instability of motivation and learning strategies, concentrating solely on the contextual level. However, it is also necessary to consider correlations with motivation levels and instability at other levels. For instance, this might involve considering the correlation between motivation levels and instability at the contextual level and learning strategies at the situational level. Finally, the present study treated the cognitive aspects of learning, specifically learning strategies (metacognitive and cognitive strategies), as dependent variables. In the future however, it will be important to conduct studies that employ school grades, emotional factors (e.g., emotional engagement, test anxiety), well-being, and so on as dependent variables.

\section{Conclusion}

This study revealed the interaction effect of identified regulation and instability of motivation on metacognitive and deep-processing strategies. The results of the analysis showed that students used these learning strategies most often when identified regulation was high, and instability of motivation was low. In other words, in order to promote the use of these effective learning strategies in school education, it is important not only to increase identified regulation, but also to reduce the instability of motivation.

\section{Acknowledgments}

This study was supported by Grant-Aid (19K14398) for Young Scientists from Japan Society for the Promotion of Science. I thank the university students for their participation. 


\section{References}

Assor, A., Vansteenkiste, M., \& Kaplan, A. (2009). Identified versus introjected approach and introjected avoidance motivations in school and in sports: The limited benefits of self-worth strivings. Journal of Educational Psychology, 101(2), 482-497. https://doi.org/10.1037/a0014236

Deci, E. L., \& Ryan, R. M. (2002). Handbook of self-determination research. The University of Rochester Press.

Eccles, J. S., \& Wigfield, A. (2002). Motivational beliefs, values, and goals. Annual Review of Psychology, 53, 109-132. https://doi.org/10.1146/annurev.psych.53.100901.135153

Guay, F., Ratelle, C. F., \& Chanal, J. (2008). Optimal learning in optimal contexts: The role of self-determination in education. Canadian Psychology/Psychologie canadienne, 49(3), 233-240. https://doi.org/10.1037/a0012758

Guay, F., Vallerand, R. J., \& Blanchard, C. (2000). On the assessment of situational intrinsic and extrinsic motivation: The situational motivation scale (SIMS). Motivation and Emotion, 24, 175-213. https://doi.org/10.1023/A:1005614228250

Ichimura, M. (2012). A study of the measure of instability of self-esteem. Japanese Journal of Personality, 20(3), 204-216. https://doi.org/10.2132/personality.20.204

Kernis, M. H., Grannemann, B. D., \& Mathis, L. C. (1991). Stability of self-esteem as a moderator of the relation between level of self-esteem and depression. Journal of Personality and Social Psychology, 61(1), 80-84. https://psycnet.apa.org/doi/10.1037/0022-3514.61.1.80

Komarraju, M., Karau, S. J., \& Schmeck, R. R. (2009). Role of the Big Five personality traits in predicting college students' academic motivation and achievement. Learning and Individual Differences, 19(1), 47-52. https://psycnet.apa.org/doi/10.1016/j.lindif.2008.07.001

Komarraju, M., Karau, S. J., Schmeck, R. R., \& Avdic, A. (2011). The Big Five personality traits, learning styles, and academic achievement. Personality and Individual Differences, 51(4), 472-477. https://doi.org/10.1016/j.paid.2011.04.019

Manalo, E., Koyasu, M., Hashimoto, K., \& Miyauchi, T. (2006). Factors that impact on the academic motivation of Japanese university students in Japan and in New Zealand. Psychologia, 49(2), 114-131. https://doi.org/10.2117/psysoc.2006.114

Marton, F., \& Säljö, R. (1976). On qualitative differences in learning: I-Outcome and process. British Journal of Educational Psychology, 46(1), 4-11. https://doi.org/10.1111/j.2044-8279.1976.tb02980.x

Miele, D. B., \& Scholer, A. A. (2017). The role of metamotivational monitoring in motivation regulation. Educational Psychologist, 53(1), 1-21. https://doi.org/10.1080/00461520.2017.1371601

Murayama, K. (2003). Test format and learning strategy use. Japanese Journal of Educational Psychology, 51(1), 1-12. https://doi.org/10.5926/jjep1953.51.1_1

Murayama, K., Pekrun, R., Lichtenfeld, S., \& Hofe, R. V. (2013). Predicting long-term growth in students' mathematics achievement: the unique contributions of motivation and cognitive strategies. Child Development, 84(4), 1475-1490. https://doi.org/10.1111/cdev.12036

Nishimura, T., Kawamura, S., \& Sakurai, S. (2011). Autonomous Motivation and Meta-Cognitive Strategies as Predictors of Academic Performance: Does Intrinsic Motivation Predict Academic Performance? Japanese Journal of Educational Psychology, 59(1), 77-87. https://doi.org/10.5926/jjep.59.77

Núñez, J. L., \& León, J. (2018). Testing the relationships between global, contextual, and situational motivation: A longitudinal study of the horizontal, top-down, and bottom-up effects. Revista de Psicodidáctica, 23(1), 9-16. https://doi.org/10.1016/j.psicoe.2017.07.003

Oshio, A. (2001). Narcissistic personality, instability of self-image, and level of self-esteem and its stability. Japanese Journal of Personality, 10(1), 35-44. https://doi.org/10.2132/jjpjspp.10.1_35

Okada, R., \& Nakaya, M. (2006). Motivational style and interest in tasks: Self-determination theory. Japanese Journal of Educational Psychology, 54(1), 1-11. https://doi.org/10.5926/jjep1953.54.1_1

Okada, R., Ohtani, K., Ito, T., \& Umemoto, T. (2015). Tendency of monitoring motivation and procrastination: An examination of the process mediated by perceived instability of motivation. Memoirs of the Faculty of Education, Kagawa University. Part I, 143, 55-61. http://shark.lib.kagawa-u.ac.jp/kuir/metadata/28283 
Otis, N., Grouzet, F. M. E., \& Pelletier, L. G. (2005). Latent motivational change in an academic setting: A 3-year longitudinal study. Journal of Educational Psychology, 97(2), 170-183. https://psycnet.apa.org/doi/10.1037/0022-0663.97.2.170

Pintrich, P. R. (1999). The role of motivation in promoting and sustaining self-regulated learning. International Journal of Educational Research, 31(6), 459-470. https://doi.org/10.1016/S0883-0355(99)00015-4

Pintrich, P. R., \& De Groot, E. V. (1990). Motivational and self-regulated learning components of classroom academic performance. Journal of Educational Psychology, 82(1), 33-40. https://psycnet.apa.org/doi/10.1037/0022-0663.82.1.33

Pintrich, P. R., Smith, D. A. F., Garcia, T., \& McKeachie, W. J. (1993). Reliability and predictive validity of the motivated strategies for learning questionnaire (MSLQ). Educational and Psychological Measurement, 53(3), 801-813. https://doi.org/10.1177/0013164493053003024

Pokay, P., \& Blumenfeld, P. C. (1990). Predicting achievement early and late in the semester: The role of motivation and use of learning strategies. Journal of Educational Psychology, 82(1), 41-50. https://psycnet.apa.org/doi/10.1037/0022-0663.82.1.41

Rosenberg, M. (1965). Society and the adolescent self-image. Princeton: Princeton University Press.

Ryan, R. M., Williams, G. C., Patrick, H., \& Deci, E. L. (2009). Self-determination theory and physical activity: The dynamics of motivation in development and wellness. Hellenic Journal of Psychology, 6(2), 107-124.

Schwinger, M., \& Stiensmeier-Pelster, J. (2012). Effects of motivational regulation on effort and achievement: A mediation model. International Journal of Educational Research, 56, 35-47. https://doi.org/10.1016/j.ijer.2012.07.005

Seufert, T. (2018). The interplay between self-regulation in learning and cognitive load. Educational Research Review, 24, 116-129. https://doi.org/10.1016/j.edurev.2018.03.004

Steinmayr, R. Weidinger, A. F., Schwinger, M., \& Spinath, B. (2019). The importance of students' motivation for their academic achievement: Replicating and extending previous findings. Frontiers in Psychology, 10, 1730. https://doi.org/10.3389/fpsyg.2019.01730

Sweller, J. (1994). Cognitive load theory, learning difficulty, and instructional design. Learning and Instruction, 4(4), 295-312. https://doi.org/10.1016/0959-4752(94)90003-5

Thompson, R., J., Dizén, M., \& Berenbaum, H. (2009). The unique relations between emotional awareness and facets of affective instability. Journal of Research in Personality, 43(5), 875-879. https://doi.org/10.1016/j.jrp.2009.07.006

Umemoto, T. (2013). The effects of metacognitive and motivational regulation strategies on the use of cognitive strategies and persistence in learning. Japanese Journal of Educational Technology, 37(1), 79-87. https://doi.org/10.15077/jjet.KJ00008721440

Umemoto, T., \& Inagaki, T. (2019). Relationship between motivational regulation strategies and instability of motivation during class. Japanese Journal of Psychology, 90(2), 207-213. https://doi.org/10.4992/jjpsy.90.18312

Umemoto, T., \& Inagaki, T. (2021). Interactive effects of level and instability of situational motivation for learning during class. Kansai University Journal of Higher Education, 12, 87-98. https://doi.org/10.32286/00022993

Umemoto, T., Ito, T., \& Tanaka, K. (2016). Relationships between regulation strategies, emotional and behavioral engagement, and academic achievement. Japanese journal of psychology, 87(4), 334-342. https://doi.org/10.4992/jjpsy.87.15020

Umemoto, T., \& Yada, N. (2012). The relationship between learning strategy, study time for a test, and test score: Measuring strategy by scale and open-ended questionnaire. Educational Psychology Forum Report, FR-2012-01, 1-8.

Vallerand, R. J., \& Lalande, D. R. (2011). The MPIC model: The perspective of the hierarchical model of intrinsic and extrinsic motivation. Psychological Inquiry, 22(1), 45-51. https://doi.org/10.1080/1047840X.2011.545366

Vallerand, R. J., Pelletier, L. G., Blais, M. R., Brière, N. M., Senécal., C., \& Vallières, E. F. (1992). The academic motivation scale: A measure of intrinsic, extrinsic, and amotivation in education. Educational and Psychological Measurement, 52(4), 1003-1017. https://doi.org/10.1177/0013164492052004025 
Vansteenkiste, M., Sierens, E., Soenens, B., Luyckx, K., \& Lens, W. (2009). Motivational profiles from a self-determination perspective: The quality of motivation matters. Journal of Educational Psychology, 101(3), 671-688. https://doi.org/10.1037/a0015083

Vansteenkiste, M., Simons, J., Lens, W., Sheldon, K. M., \& Deci, E. L. (2004). Motivating learning, performance, and persistence: The synergistic effects of intrinsic goal contents and autonomy-supportive contexts. Journal $\begin{array}{lllll}\text { of Personality and Social } & \text { Psychology, }\end{array}$ https://psycnet.apa.org/doi/10.1037/0022-3514.87.2.246

Walker, C. O., Greene, B. A., \& Mansell, R. A. (2006). Identification with academics, intrinsic/extrinsic motivation, and self-efficacy as predictors of cognitive engagement. Learning and Individual Differences, 16(1), 1-12. https://psycnet.apa.org/doi/10.1016/j.lindif.2005.06.004

Walls, T. A., \& Little, T. D. (2005). Relations among personal agency, motivation, and school adjustment in early $\begin{array}{lllll}\text { adolescence. Journal of } & \text { Educational Psychology, }\end{array}$ https://psycnet.apa.org/doi/10.1037/0022-0663.97.1.23

Weinstein, C. E., \& Mayer, R. (1986). The teaching of learning strategies. In M.C. Wittrock (Ed.), Handbook of research on teaching. Third edition (pp. 315-327). Collier Macmillan Publishers.

Wentzel, K. R., \& Miele, D. B. (2016). Handbook of motivation at school. Second edition. Routledge. https://doi.org/10.4324/9781315773384

Wolters, C. A. (1999). The relation between high school students' motivational regulation and their use of learning strategies, effort, and classroom performance. Learning and Individual Differences, 11(3), 281-299. https://doi.org/10.1016/S1041-6080(99)80004-1

Zimmerman, B. J., \& Partinez-Pons, M. (1986). Development of a structured interview for assessing student use of self-regulated learning strategies. American Educational Research Journal, 23(4), 614-628. https://doi.org/10.3102/00028312023004614

\section{Notes}

Note 1. Organismic integration theory assumes integrated regulation as the most autonomous type of extrinsic motivation. It refers to motivation as the value of doing and participating in a task, while being fully internalized and in perfect harmony with the person's values, goals, and needs (e.g., Deci \& Ryan, 2002). However, in previous studies (Vallerand et al., 1992), integrated regulation was not statistically discriminated from identified regulation. As it was rarely dealt with in subsequent empirical studies (Nishimura et al., 2011), this study did not mention integrated regulation.

\section{Appendix}

\section{Scale items used in this study}

\section{Introjected regulation}

Because I do not want to lag behind the people around me.

Because I would feel anxious if I did not do it.

Because I want to get good grades and evaluations.

Because I am given what I have to do, such as learning tasks.

Because I want to show my competence to the people around me.

Because it is like a rule.

Because I do not want to be worried later.

Because I will feel guilty if I do not do it.

Because I will feel embarrassed if I do not do it

Because I have to do it.

Because it has become necessary in society, today.

Because I want to make a good impression on the people around me. 
Because I am forced to do it.

Because I can feel my own value through doing it.

Because I do not want to make my parents sad.

\section{Identified regulation}

Because it will be useful in various ways in the future.

Because it will lead to future success.

Because it is necessary for employment examinations and occupations

Because learning itself is important.

\section{Instability of motivation}

My motivation for university learning is very liable to change.

My motivation for learning changes considerably from one day to the next.

My motivation for university learning changes constantly.

There are days when I am very motivated, and days when I am not motivated at all.

I think that my motivation for learning unchanges at all (reverse coded item).

\section{Metacognitive strategies}

I study according to my study plan.

I consider whether the way I study is right for me while I study.

Before I start studying, I think about what and how I will study.

I check whether I remember the content while I am studying.

Before I start studying, I make a study plan.

I try to identify things that I do not understand when I study.

Writing-repetition strategy

When I learn, I learn by writing the content down.

When remembering terms and so on, I learn by writing them down.

When remembering terms and so on, I remember them by writing them repeatedly.

Deep-processing strategy

I remember what I have already studied while I am studying.

When I study, I remember similar contents together.

I imagine the contents while I am studying.

When I memorize the terms or contents, I put similar information together.

When I study, I remember the contents by making connections with other contents.

When I study, I relate the new information with what I have already learned.

\section{Copyrights}

Copyright for this article is retained by the author(s), with first publication rights granted to the journal.

This is an open-access article distributed under the terms and conditions of the Creative Commons Attribution license (http://creativecommons.org/licenses/by/4.0/). 